\title{
Srrm234, but not canonical SR and hnRNP proteins, drive inclusion of Dscam exon 9 variable exons
}

\author{
PINAR USTAOGLU, ${ }^{1,7}$ IRMGARD U. HAUSSMANN, ${ }^{1,2}$ HONGZHI LIAO, ${ }^{1,8}$ ANTONIO TORRES-MENDEZ, ${ }^{3}$ \\ ROLAND ARNOLD, ${ }^{4}$ MANUEL IRIMIA, ${ }^{3,5,6}$ and MATTHIAS SOLLER ${ }^{1}$ \\ ${ }^{1}$ School of Biosciences, College of Life and Environmental Sciences, University of Birmingham, Edgbaston, Birmingham B15 2TT, \\ United Kingdom \\ ${ }^{2}$ Department of Life Science, School of Health Sciences, Birmingham City University, Birmingham B5 3TN, United Kingdom \\ ${ }^{3}$ Centre for Genomic Regulation, Barcelona Institute of Science and Technology (BIST), Barcelona 08003, Spain \\ ${ }^{4}$ Institute of Cancer and Genomics Sciences, College of Medical and Dental Sciences, University of Birmingham, Edgbaston, \\ Birmingham B15 2TT, United Kingdom \\ ${ }^{5}$ Universitat Pompeu Fabra (UPF), Barcelona 08003, Spain \\ ${ }^{6}$ ICREA, Barcelona 08010, Spain
}

\begin{abstract}
Alternative splicing of pre-mRNA is a major mechanism to diversify protein functionality in metazoans from a limited number of genes. The Drosophila melanogaster Down syndrome cell adhesion molecule (Dscam) gene, which is important for neuronal wiring and phagocytosis of bacteria, can generate up to 38,016 isoforms by mutually exclusive alternative splicing in four clusters of variable exons. However, it is not understood how a specific exon is chosen from the many variables and how variable exons are prevented from being spliced together. A main role in the regulation of Dscam alternative splicing has been attributed to RNA binding proteins (RBPs), but how they impact on exon selection is not well understood. Serinearginine rich (SR) proteins and hnRNP proteins are the two main types of RBPs with major roles in exon definition and splice site selection. Here, we analyzed the role of SR and hnRNP proteins in Dscam exon 9 alternative splicing in mutant Drosophila melanogaster embryos because of their essential function for development. Strikingly, loss or overexpression of canonical SR and hnRNP proteins even when multiple proteins are depleted together, does not affect Dscam alternative exon selection very dramatically. Conversely, noncanonical SR protein Serine-arginine repetitive matrix 2/3/4 (Srrm234) is a main determinant of exon inclusion in the Dscam exon 9 cluster. Since long-range base-pairings are absent in the exon 9 cluster, our data argue for a small complement of regulatory factors as main determinants of exon inclusion in the Dscam exon 9 cluster.
\end{abstract}

Keywords: alternative splicing; Dscam; RNA binding proteins; SR proteins; SRm300; hnRNP proteins

\section{INTRODUCTION}

During alternative splicing, the combination of exons can be varied to generate multiple different transcripts and proteins from one gene (Soller 2006; Nilsen and Graveley 2010; Fiszbein and Kornblihtt 2017). In humans, 95\% of genes, and in Drosophila melanogaster $63 \%$ of genes are alternatively spliced, respectively (Wang et al. 2008; $\mathrm{Fu}$ and Ares 2014). Among the genes where alternative

\footnotetext{
${ }^{7}$ Present address: MRC Centre for Molecular Bacteriology and Infection, and Department of Life Sciences, Imperial College London, London SW7 2AZ, UK

${ }^{8}$ Present address: Zhongkai University of Agriculture and Engineering, Haizhu District, 510080, Guangzhou, China

Corresponding author: m.soller@bham.ac.uk

Article is online at http://www.rnajournal.org/cgi/doi/10.1261/rna. 071316.119.
}

splicing generates the greatest diversity of isoforms is the Drosophila melanogaster homolog of human Down syndrome cell adhesion molecule (Dscam) gene, which encodes a cell surface protein of the immunoglobulin superfamily. The Dscam gene comprises 95 alternatively spliced exons that are organized into four clusters, namely 4, 6, 9, and 17 , which contains $12,48,33$, and two variables, respectively. Hence, the Dscam gene can generate up to 38,016 different proteins (Schmucker et al. 2000; Neves et al. 2004; Hemani and Soller 2012; Sun et al. 2013).

(C) 2019 Ustaoglu et al. This article is distributed exclusively by the RNA Society for the first 12 months after the full-issue publication date (see http://rnajournal.cshlp.org/site/misc/terms.xhtml). After 12 months, it is available under a Creative Commons License (Attribution-NonCommercial 4.0 International), as described at http:// creativecommons.org/licenses/by-nc/4.0/. 
Dscam is functionally required for neuronal wiring in the nervous system, but also for phagocytosis of invading pathogens in the immune system (Schmucker et al. 2000; Watson et al. 2005). Interestingly, Dscam in mosquitos changes its splicing pattern upon pathogen exposure to produce isoforms with higher binding affinity for binding pathogen (Dong et al. 2006). However, despite intense research, relatively little is known about how Dscam alternative splicing is regulated in flies.

Pre-mRNA splicing is a multistep process catalyzed by the spliceosome sequentially assembled from five $U$ snRNPs together with numerous proteins. Spliceosome assembly initiates by the recognition of the $5^{\prime}$ splice site by U1 snRNP and of the 3' splice site by U2 snRNP, together with U2AFs recognizing the branchpoint and the polypyrimidine tract and the AG of the $3^{\prime}$ splice site, respectively. Then the U4/5/6 tri-snRNP is recruited, and upon several structural rearrangements where U4 snRNP leaves the spliceosome, catalysis takes place by two transesterification reactions (Lührmann and Stark 2009).

Alternative splicing is to a large degree regulated at the level of splice site recognition involving base-pairing of U1 snRNP to the $5^{\prime}$ splice site YAG/GURAGU and U2 to the branchpoint WNCUAAU (W: A or U, Drosophila melanogaster consensus; Lim and Burge 2001) whereby splice sites closer to the consensus are preferably used (Soller 2006). Splice site selection is critically assisted by RNA binding proteins (RBPs) that support or inhibit recognition of splice sites.

Serine-arginine rich (SR) and heterogenous nuclear ribonucleoproteins ( $h n R N P s$ ) are two prominent classes of RBPs involved in alternative splicing regulation (Busch and Hertel 2012; Fu and Ares 2014; Bradley et al. 2015). Humans have twelve and flies have eight SR proteins, each having one or two RNA recognition motifs (RRM) and RS domain rich in serines and arginines (Busch and Hertel 2012). In addition, RS domains are present in some other splicing factors lacking RNA binding domains such as Tra2, SRRM1 (SRm160), and SRRM2 (SRm300), SRRM3, and SRRM4 (nSR100), which are termed noncanonical SR proteins (Blencowe et al. 1999; Long and Caceres 2009; Busch and Hertel 2012; Best et al. 2014). In contrast, hnRNP proteins are more diverse in their modular assembly containing RNA binding domains (e.g., RRM, KH, or RGG domains) and various auxiliary domains (Geuens et al. 2016). In humans, the most prominent hnRNPs are the abundantly expressed hnRNP A and C family (Busch and Hertel 2012; Geuens et al. 2016).

SR proteins mostly bind to exonic splicing enhancers (ESEs) and recruit spliceosomal components to splice sites through their RS domains. SR protein binding sites are present in both alternatively spliced and constitutive exons to promote exon inclusion, but they can also repress inclusion of alternative exons (Black 2003; Shen et al. 2004; Wang et al. 2006; Chen and Manley 2009; Pandit et al.
2013). Although SR proteins recognize similar sequences, distinct functions have been shown either by binding distinct sites or when bound to the same site through differential regulation mediated by combinatorial interactions with other splicing regulators (Gabut et al. 2007; Änkö et al. 2012; Pandit et al. 2013; Bradley et al. 2015).

In contrast to SR proteins, hnRNP proteins mostly bind to intronic splicing silencers (ISSs) and repress inclusion of alternative exons (House and Lynch 2006; Wang et al. 2008). In addition, they can act antagonistically to SR proteins by binding to exonic splicing silencers (ESSs) and compete with SR proteins for binding (Soller 2006; Long and Caceres 2009). However, a more comprehensive analysis revealed that SR and hnRNP proteins can also act coordinately in many instances in exon inclusion or repression (Brooks et al. 2015).

With regard to the alternative splicing in the Dscam gene, a model has been proposed for the exon 6 cluster involving long-range base-pairing. Here, a conserved docking sequence in the first intron of the exon 6 clusters can base-pair with complementary selector sequences in front of each variable exon to bring a chosen variable exon into the proximity of the proximal constant flanking exon for splicing (Graveley 2005). This model also requires that the entire cluster is maintained in a repressed state and variable exons are selected under the control of RBPs. However, the architecture in the exon 4 and 9 clusters is different and conserved "docking site" sequences are found at the end of the exon 4 and 9 clusters, but the support for this model based on evolutionary sequence conservation is weak (Yang et al. 2011; Haussmann et al. 2019).

RNAi knockdown of RBPs in cell culture in Drosophila melanogaster $\mathrm{S} 2$ cells revealed little changes for most variable exons in the Dscam exon 4 cluster, but this result could be due to residual protein that is left (Park et al. 2004). Hence, we wanted to investigate the role of SR and hnRNP proteins in Drosophila melanogaster Dscam alternative splicing more comprehensively at an organismal level using knockout mutants and overexpression. Most SR and hnRNP proteins are essential for development to adult flies, but embryonic development proceeds such that Dscam alternative splicing could be analyzed in late-stage embryos in SR and hnRNP mutants or when overexpressed. Unexpectedly, we find that inclusion of Dscam exon 9 variables is affected little in loss or gain of function (GOF) conditions. Likewise, even upon removal even of multiple factors, Dscam exon 9 alternative splicing changes little. However, the noncanonical SR protein Serinearginine repetitive matrix $2 / 3 / 4$ (Srrm234) is required for inclusion of most exon 9 variables. We further find that long-range base-pairing is not supported as a general model. Hence, our results argue that a small complement of RBPs are the main regulators of Dscam exon 9 alternative splicing. 


\section{RESULTS}

Analysis of Dscam exon 9 alternative splicing by restriction digests

All 33 exons in the Drosophila melanogaster Dscam exon 9 variable exon cluster have about the same length and run as a single band on an agarose gel (Fig. 1A,B). The sequences in variable exons, however, differ enough such that a complement of restriction enzymes can digest the complex mix of PCR products to identify a majority of isoforms on sequencing type gels using one ${ }^{32} \mathrm{P}$ labeled primer after reverse transcription of the mRNA (Fig. 1C,D; Haussmann et al. 2019). Using a combination of Sacll, Clal, PshAl, Haelll, Msel, Bsrl, and BstNI yields 26 fragments of unique size identifying 20 variable exons (Fig. 1D).

\section{Alteration of SR proteins has little impact on Dscam exon 9 alternative splicing}

SR proteins are organized into five families and representative orthologues are present in Drosophila melanogaster (Fig. 2; Busch and Hertel 2012). To determine the role of $S R$ proteins in Drosophila melanogaster Dscam exon 9 alternative splicing we obtained mutants and overexpression lines for most of the canonical SR proteins as well as for general splicing factor SF1 and noncanonical SR protein Srrm1 (SRm160) and Srrm234 (SRm300, CG7971) (Fig. 2A; Supplemental Fig. S1). For loss of function (LOF) alleles of SR genes, five from the

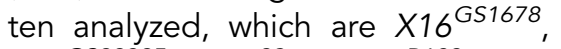
SF2 ${ }^{\text {GS22325, }}$ B52 ${ }^{29}, \mathrm{Srrm}^{1{ }^{103}}{ }^{\text {, and }}$ Srrm $234^{\Delta N}$, are required to 'reach adulthood (Fig. 2A,B). Gain of function conditions by pan-neural elavGAL4 mediated overexpression via UAS was lethal in larval instars for UAS GFP-X16, UAS RSF1, UAS GFP-SC35, UAS GFP-SF2, and UAS GFP-B52, while overexpression of UAS SF1 and UAS Srrm1 from EP lines did not result in a phenotype (Fig. 2A,C).

A

B
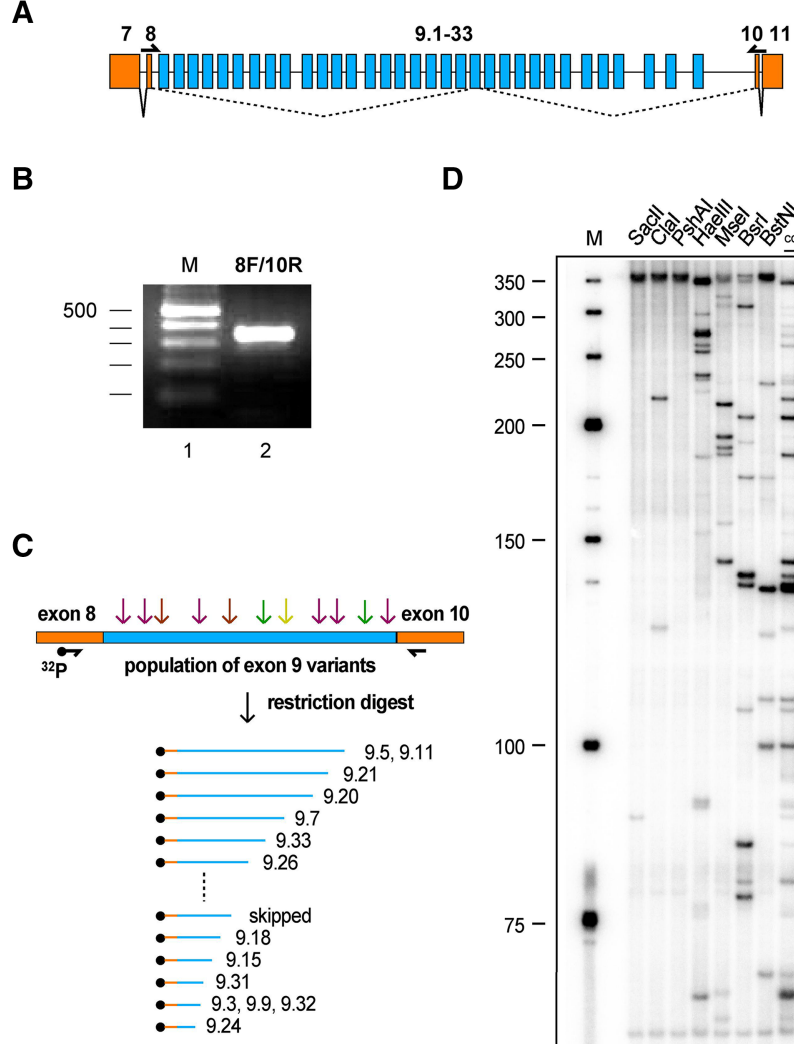

D

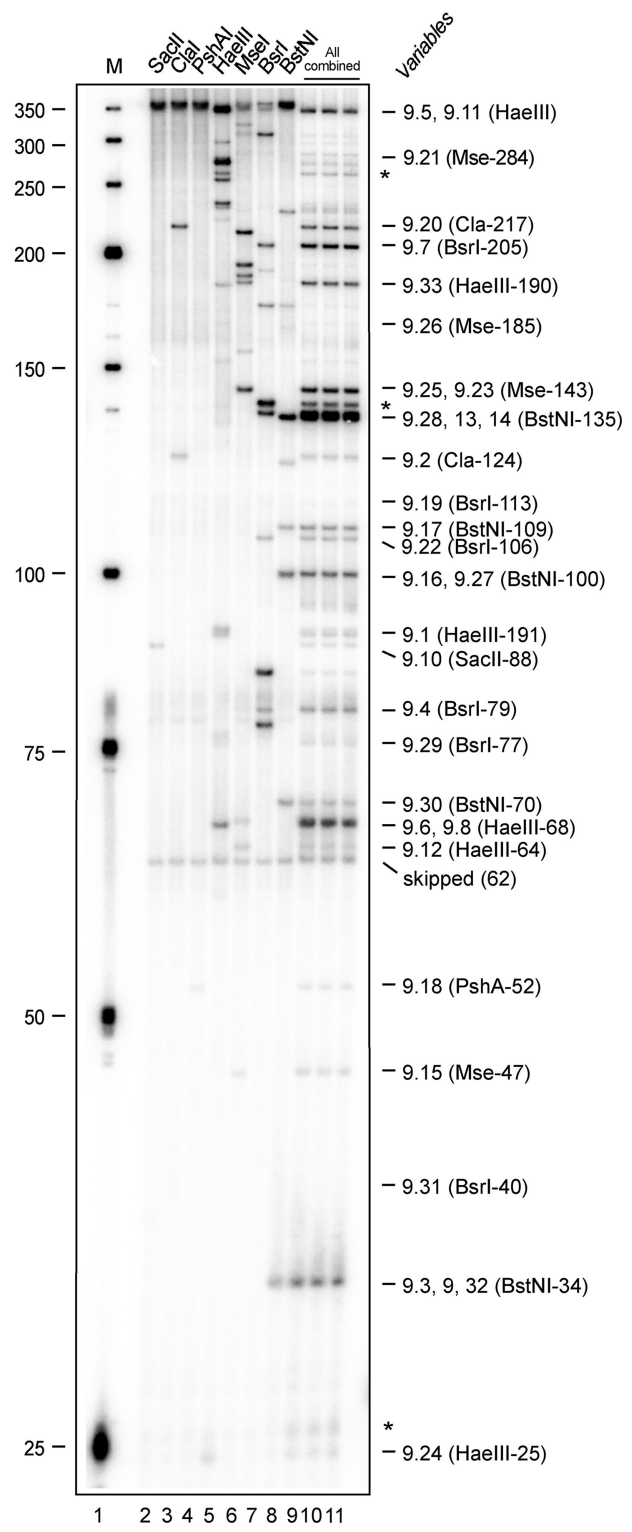

FIGURE 1. Analysis of Dscam exon 9 alternative splicing by restriction digestion of PCR products. (A) Schematic of the Dscam exon 9 variable cluster gene region. Constitutive exons are shown in orange and variable exons in blue. Primers to amplify the variable part are shown below the exons. (B) RT-PCR product for variable exon cluster 9 shown on a $3 \%$ agarose gel. (C) Schematic of the method used to resolve inclusion levels of variable exons using a ${ }^{32} \mathrm{P}$ labeled forward primer in combination with a set of restriction enzymes followed by separation of a denaturing polyacrylamide gel. (D) Denaturing acrylamide gel (6\%) showing a restriction digest (Sacll, Clal, PshAl, Haelll, Msel, Bsrl, BstNI) of Dscam exon 9 variables amplified with a ${ }^{32} \mathrm{P}$ labeled forward primer from 14-18 h Drosophila embryos. Single enzyme reference digests are shown on the left (lanes 2-8) and the combination of all enzymes on the right (lanes 9-11).
Next, we analyzed inclusion levels of exon 9 variables in embryos for LOF and GOF conditions of canonical SR proteins and SF1. For LOF alleles X16 ${ }^{\mathrm{GS} 1678}, \mathrm{RBP} 1^{\text {HP37044, }}$ 
A

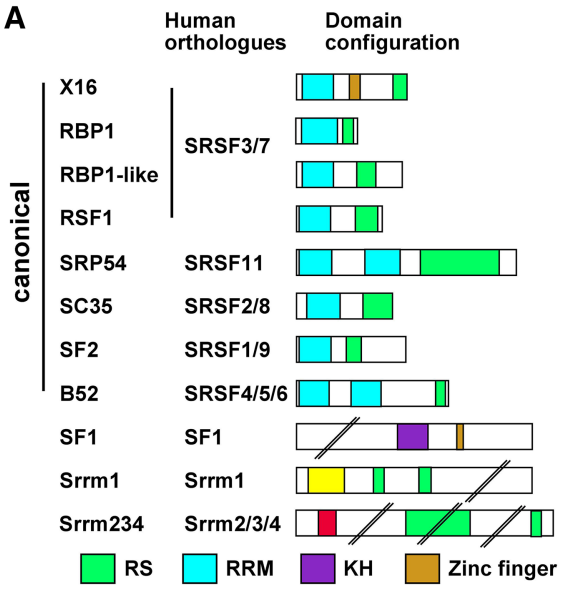

\begin{tabular}{|c|c|c|}
\hline $\begin{array}{l}\text { Mutant } \\
\text { allele }\end{array}$ & $\begin{array}{l}\text { LOF } \\
\text { phenotype }\end{array}$ & $\begin{array}{l}\text { GOF } \\
\text { phenotype }\end{array}$ \\
\hline null & lethal & larval lethal \\
\hline hypomorph & viable & no line \\
\hline null & viable & no line \\
\hline no line & n.a. & larval lethal \\
\hline null & viable & viable \\
\hline null & viable & larval lethal \\
\hline null & lethal & larval lethal \\
\hline null & lethal & larval lethal \\
\hline null & viable & viable \\
\hline null & lethal & viable \\
\hline null & lethal & no line \\
\hline PWI & CWF21 & \\
\hline
\end{tabular}

B
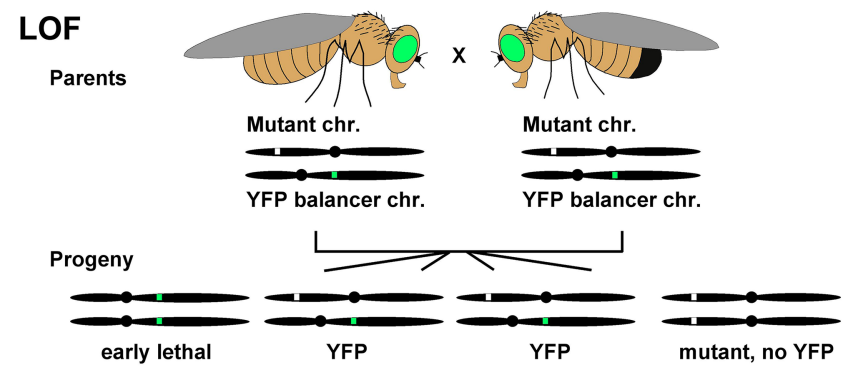

C

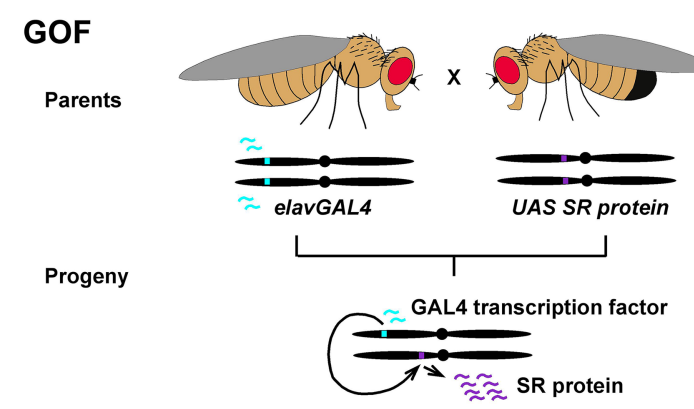

FIGURE 2. Protein domain structure of Drosophila SR proteins and phenotype of LOF and GOF mutants. (A) Evolutionary relationship of Drosophila SR proteins with human homologs is shown on the left and the domain structure is indicated by colored boxes. Arginineserine rich domain (RS, green), RNA recognition domain (RRM, light blue), hnRNP K homology domain (KH, purple), zinc finger domain (ochre), Proline-Tryptophan-Isoleucine domain (PWI, yellow) and CWF21 domain (red). The type of allele obtained, and the loss (LOF) and GOF phenotypes are indicated on the right. (B) Viability was determined from stocks that harbor a zygotically expressing GFP marked balancer chromosome, which contains a set of inversions to suppress recombination, and a recessive lethal mutation. If a gene is essential, only heterozygous flies will survive. Homozygous mutant embryos were identified in the progeny of these stocks by the lack of GFP and advanced development as homozygous balancer carrying embryos die early before GFP expression. (C) To obtain embryos overexpressing SR proteins, flies carrying the yeast GAL4 transcription factor under the control of the pan-neuronal elav promoter were crossed with lines harboring SR proteins under the control of the yeast UAS promoter.

RBP1-like ${ }^{\mathrm{NP0295}}, \mathrm{Srp54} 4^{\mathrm{GS} 15334}, \mathrm{SC} 35^{\mathrm{KGO2986}}, \mathrm{SF} 2^{\mathrm{GS} 22325}$ $B 52^{28}$, and SF1 ${ }^{G 14313}$ the Dscam exon 9 splicing pattern unexpectedly remained largely unchanged and significant changes are prominent in exon 9.4, 9.21, and 9.5/9.11 for mutants compared to wild-type (marked in red for decrease and blue for increase, Fig. 3A,B). Similar results were obtained for overexpression of UAS GFP-X16, UAS RSF1, UAS GFPSC35, UAS GFP-SF2, UAS GFP-B52, and UAS-Srrm 1 with significant changes only prominent in exon 9.19 and 9.21 for GOF conditions compared to wild-type (marked in red for decrease and blue for increase, Fig. $3 C, D)$.

\section{Noncanonical SR protein Srrm234 is required for the selection of Dscam exon 9 variables}

The canonical SR proteins contain an RRM and bind to RNA. In contrast, the large Srrm1 and Srrm234 proteins contain RS domains, but seem not to bind RNA and exert splicing enhancing functions through association with proteins bound to ESEs (Fig. 2; Blencowe et al. 1998, 2000; Eldridge et al. 1999; Szymczyna et al. 2003).

We obtained null mutants for both genes, Srrm $1^{\mathrm{B} 103}$ and Srrm $234^{\Delta \mathrm{N}}$, which are late embryonic lethal (Fan et al. 2014). While loss of Srrm 1 had little effect on Dscam exon splicing, loss of Srrm234 resulted in significant reduction in inclusion for many variable exons (marked in red, 9.4, 9.7, $9.10,9.16 / 9.27,9.17,9.18,9.20$, $9.23 / 9.25,9.29$, and 9.33) that is compensated by increased inclusion of a few variable exons (marked in blue, 9.3/9.32, 9.6/9.8, 9.12, and 9.30) (Fig. 4A,B). Consistent with a role in Dscam exon 9 alternative splicing regulation, Srrm234 is also expressed in the nervous system of Drosophila melanogaster embryos in the same pattern as Dscam (Supplemental Fig. S2).

\section{Alteration of hnRNP proteins has little impact on Dscam exon 9 alternative splicing}

Since alterations of individual canonical SR proteins had little impact on selection of Dscam exon 9 variables, we focused on hnRNP proteins as candidates for repressing inclusion of exon 9 variables (Olson et al. 2007; Chen and Manley 2009; Fu and Ares 2014). Drosophila melanogaster has four members of the highly expressed hnRNP A family (Hrp36, Hrp38, Rb97D, and Hrp48) and one member of the 
A
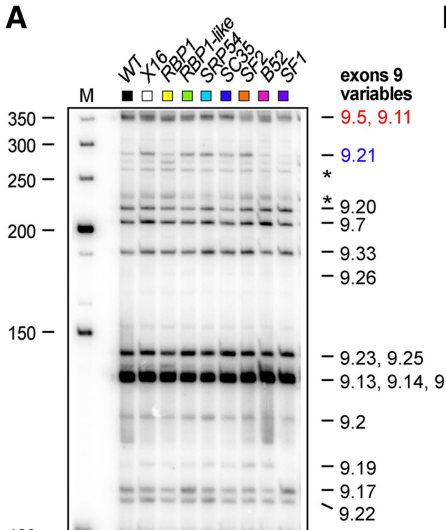

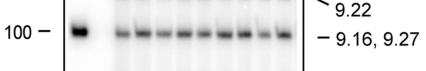
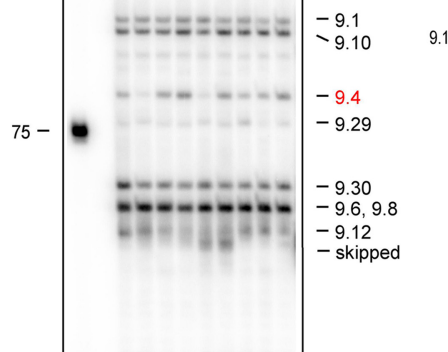

$50-$

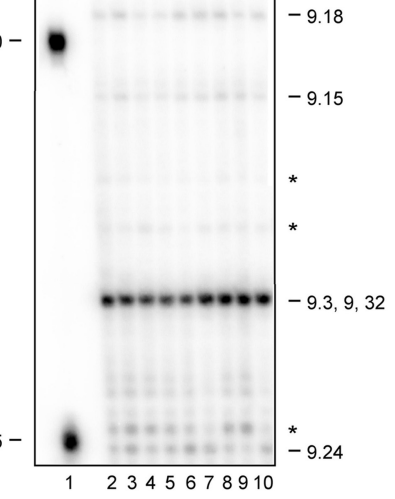

WT $\square$ RBP1 $\square$ Srp54 $\square$ SF2 $\square$ SF1 $\square X 16 \square$ RBP1-like $\square$ SC35 $\square B 52$
B

exons 9

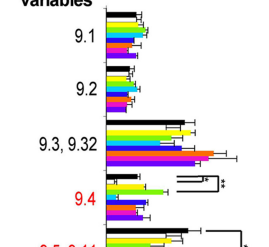

9.28
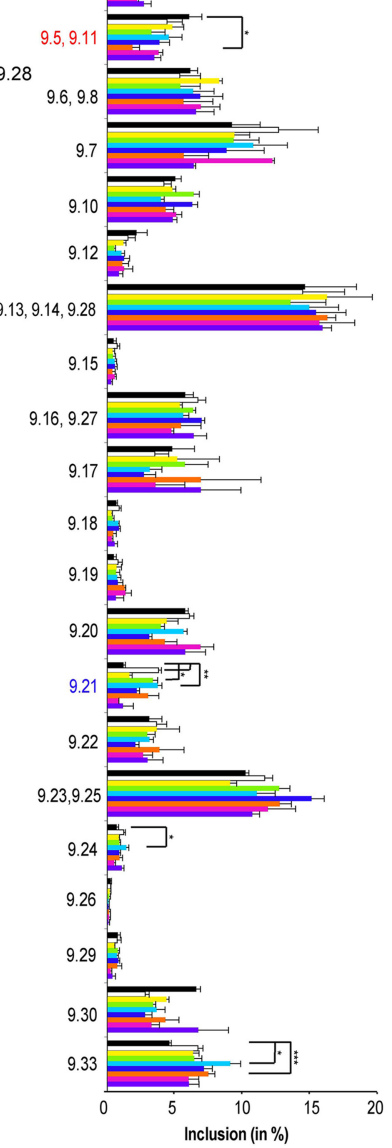

sF1

Inclusion (in \%)
C

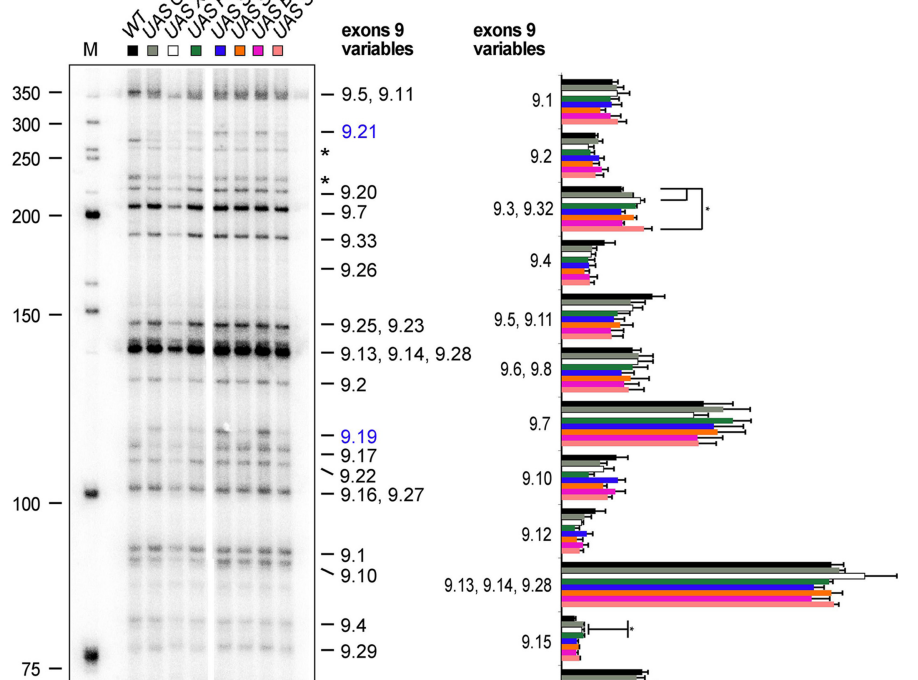

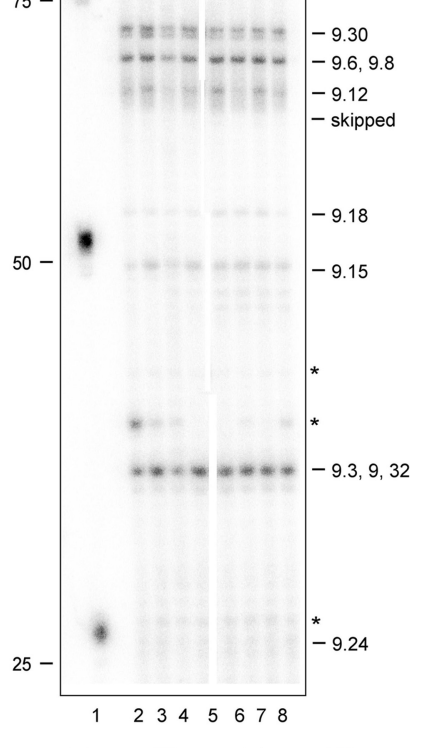

WT $\square X 16 \quad \square S C 35 \square B 52$

$\square$ GFP $\square$ RSF1 $\square$ SF2 $\square$ Srrm1

9.16,9.27

${ }_{9.17}$

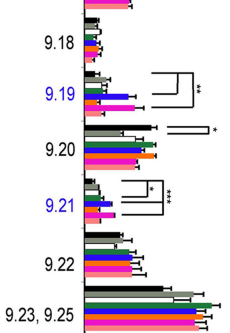

D

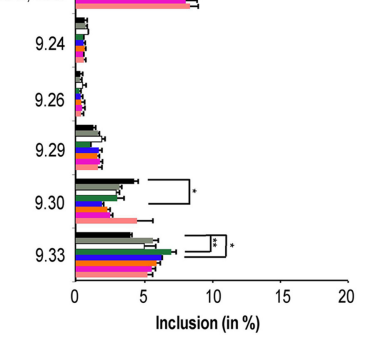

FIGURE 3. Analysis of Dscam exon 9 alternative splicing in canonical SR protein LOF and GOF mutants. $(A, C)$ Denaturing acrylamide gel showing restriction digests of Dscam exon 9 variables amplified with a ${ }^{32} \mathrm{P}$ labeled forward primer from 14-18 h Drosophila embryos for canonical SR protein LOF $(A)$ and elavGAL4 UAS GOF mutants $(C)$. Quantification of inclusion levels are shown as means with standard error from three experiments for canonical SR protein LOF $(B)$ and GOF mutants $(D)$. Prominent changes in inclusion levels in mutants compared to wild-type are marked with red letters for a decrease and in blue for an increase, and statistically significant differences are indicated by asterisks. $\left({ }^{* * *}\right) P \leq 0.001,\left({ }^{* *}\right) P \leq$ $0.01,\left({ }^{*}\right) P \leq 0.05$.

hnRNP C, although the Drosophila melanogaster orthologue is considerably longer (Fig. 5; Appocher et al. 2017). Other highly expressed hnRNP proteins are Hrp40 (hnRNP D), Glorund (hnRNP F/H), Hrb57A (hnRNP K), and Hrb59 (hnRNP M).

To determine the role of hnRNP proteins in Drosophila melanogaster Dscam exon 9 alternative splicing we could obtain null-mutants for all major hnRNP proteins $\left(H_{r p 36}{ }^{B G 02743}, H r p 38^{M 11059}, R B 97 D^{1}, H_{r p 48}^{G S 14498}\right.$, Hrp40 ${ }^{G S 18188}$, glofo2674, Hrb57 ${ }^{\mathrm{G13574}}$, and Hrp59GS6029) and gene-switch or EP overexpression lines for most (Hrp36 ${ }^{\mathrm{GS} 15926}, \mathrm{Hrp38}^{\mathrm{GS} 12795}, \mathrm{Hrp}{ }^{\mathrm{EY} 12571}$, and Hrp59 ${ }^{G S 6029}$, Figs. 5, 7A; Supplemental Fig. S3). Half of the tested major hnRNP genes are required for viability (Rb97D, Hrp40, glo, and Hrp59), while only overexpression of Hrp36 was lethal (Fig. 5).

Then, we analyzed Dscam exon 9 inclusion levels for LOF and GOF of hnRNPs. For LOF alleles, the Dscam exon 9 splicing pattern also unexpectedly remained largely unchanged and significant changes are prominent in exon 9.17, 9.19, and 9.21 for mutants compared to wildtype (marked in red for decrease and blue for increase, 
A

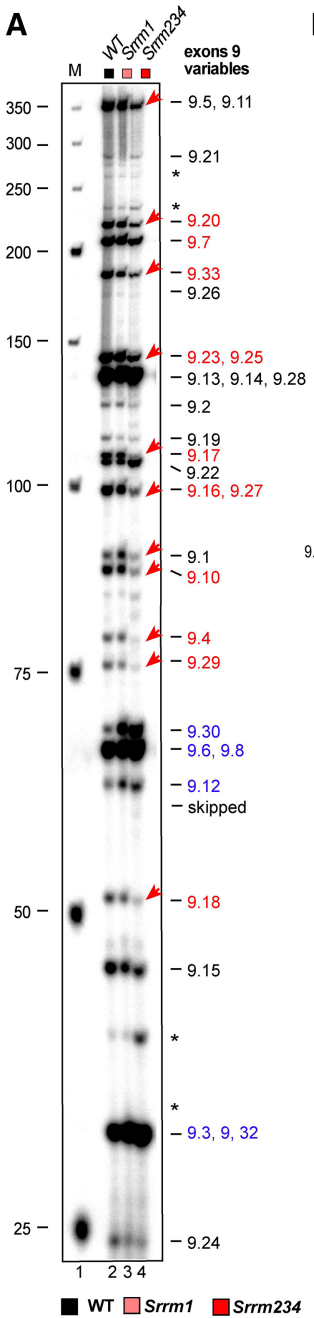

B exons 9
varables

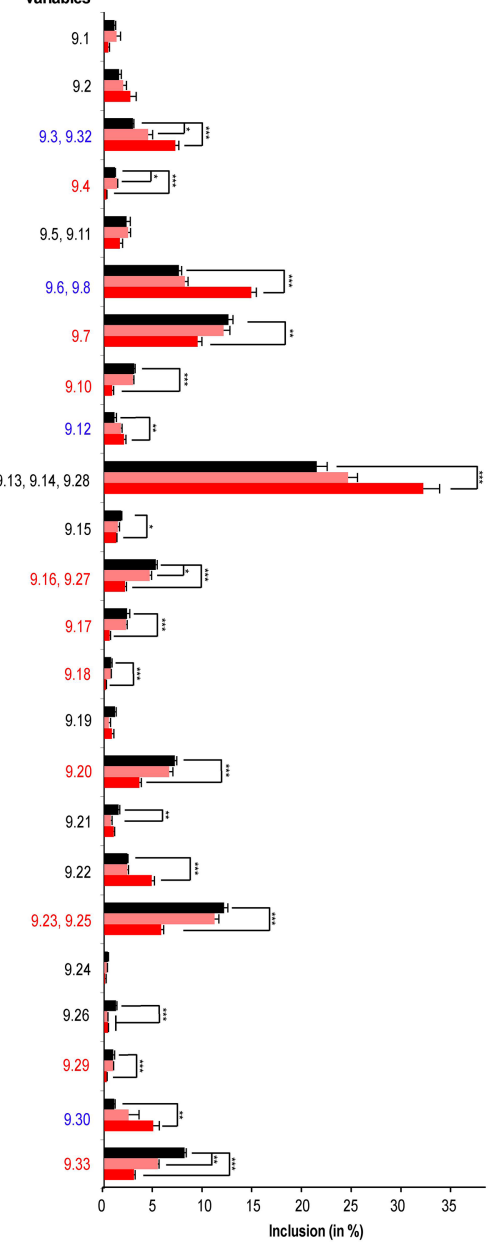

FIGURE 4. Analysis of Dscam exon 9 alternative splicing in noncanonical SR proteins Srrm1 and Srrm234 LOF mutants. (A) Denaturing acrylamide gel showing restriction digests of Dscam exon 9 variables amplified with a ${ }^{32} \mathrm{P}$ labeled forward primer from 14-18 $\mathrm{h}$ Drosophila embryos for Srrm1 and Srrm234 protein LOF mutants. Quantification of inclusion levels is shown as means with standard error from three experiments $(B)$. Red arrows point toward exons with reduced inclusion levels in the Srrm $234^{\Delta \mathrm{N}}$ mutant compared to wildtype. Prominent changes in inclusion levels are marked with red letters for a decrease and in blue for an increase in the Srrm $234^{\Delta N}$ mutant compared to wild-type. Statistically significant differences are indicated by asterisks. $\left(^{* * *}\right) P \leq 0.001,\left(^{* *}\right) P \leq 0.01,\left({ }^{*}\right) P \leq 0.05$

Fig. 6A,B). Similar results were obtained for GOF conditions with significant changes only prominent in exon 9.2, 9.4, 9.17, 9.19, 9.21, and 9.30 (marked in red for decrease and blue for increase, Fig. 6C,D).

Binding of Hrp36, Hrp38, Hrp48, and Hrp40 to RNA has been analyzed globally in Drosophila melanogaster and binding motifs have been established by SELEX (Blanchette et al. 2009). When we reanalyzed these data we did find significantly increased binding for all four Hrp proteins $(P<0.05)$ to the Dscam exon 9 variable cluster compared to averaged binding, but the binding curves did

not overlap with changes in exon inclusion in LOF or GOF conditions (Supplemental Fig. S4). Likewise, we did not find an overlap of SELEX motif enrichments with changes in exon inclusion in LOF or GOF conditions (Supplemental Fig. S4).

\section{Removal of multiple SR and hnRNP proteins has little impact on selection of Dscam exon 9 variables}

hnRNP36 and SR protein B52 genes lie next to each other in the Drosophila melanogaster genome and potentially could cross-regulate to compensate for each other (Fig. 7A). Therefore, we generated a double knockout of hnRNP36 and B52 genes (hnRNP36/B52 ${ }^{41}$ ). In addition, we also combined this double knockout with the hnRNP38 mutant as hnRNP36 and hnRNP38 are closely related and since they are highly expressed, they could act redundantly.

Surprisingly, even in hnRNP36/B52 $2^{41}$ hnRNP38 ${ }^{d 05172}$ triple mutants, Dscam exon 9 was robustly spliced with only differences in inclusion levels of variables 9.4, 9.16/9.27, $9.17,9.18,9.19$, and 9.21 compared to controls (marked in red for decrease and blue for increase, Figure 7B,C).

\section{Variable exon selection is not explained by long- range base-pairing in Dscam exon 9}

In the exon 4 cluster, we could not detect conserved sequences adjacent to every variable exon that could mediate long-range base-pairing arguing that such a mechanism is not involved in variable exon 4 selection (Haussmann et al. 2019). A sequence alignment between Drosophila melanogaster and Drosophila virilis showed strong conservation in the coding sequences and the architecture of the exon 9 cluster with only few insertions and deletions of exons (Supplemental Fig. S5). There are conserved sequence elements in the intron before constant exon 10 that potentially could serve as a docking site (Yang et al. 2011), but we did not find conserved sequence elements between every variable exon by manual inspection (Supplemental Fig. S6). A systematic bioinformatics comparison of this potential docking site with arbitrary sampled sequences of the same length and sequence complexity further did not reveal a special propensity of the docking site to form more or stronger complementary alignments within Dscam intronic sequences in the variable exon 9 cluster. The same picture arises when comparing predicted energies of the best secondary duplex structures formed by the reverse intronic sequence, the docking site, and sampled sequences (Supplemental Fig. S7). In addition, we did not find other instances of the docking site in any other gene of $D$. melanogaster (except in the anti-sense RNA CR45129 of Dscam), indicating that the sequence is not recurrent in other genes. 


\begin{tabular}{|c|c|c|c|c|c|}
\hline & $\begin{array}{l}\text { Human } \\
\text { orthologues }\end{array}$ & $\begin{array}{l}\text { Domain } \\
\text { configuration }\end{array}$ & $\begin{array}{l}\text { Mutant } \\
\text { allele }\end{array}$ & $\begin{array}{l}\text { LOF } \\
\text { phenotype }\end{array}$ & $\begin{array}{l}\text { GOF } \\
\text { phenotype }\end{array}$ \\
\hline Hrp36 & & ए & null & viable & larval lethal \\
\hline Hrp38 & hnRNP A & & null & viable & viable \\
\hline Rb97D & nnRiNe A & & null & lethal & no line \\
\hline Hrp48 & & & null & viable & viable \\
\hline CG42458 & hnRNP C & & n.a. & no line & no line \\
\hline Hrp40 & hnRNP D & & null & semi-lethal & no line \\
\hline Glo & hnRNP F/H & $\square$ & null & lethal & no line \\
\hline Hrb57A & hnRNP K & $\square$ & hypomorph & viable & no line \\
\hline Hrp59 & hnRNP M & \begin{tabular}{|l|l|} 
& \\
\end{tabular} & null & lethal & viable \\
\hline
\end{tabular}

FIGURE 5. Protein domain structure of Drosophila hnRNP proteins and phenotype of LOF and GOF mutants. Evolutionary relationship of Drosophila hnRNP proteins with human homologs is shown on the left and the domain structure is indicated by colored boxes. RNA recognition domain (RRM, light blue) and hnRNP K homology domain (KH, purple). The type of allele obtained, and the loss (LOF) and gain of function (GOF) phenotypes are indicated on the right.

\section{DISCUSSION}

Although the sequence determinants that direct the spliceosome to its correct position are very degenerate, splicing needs to occur precisely and with high accuracy to prevent disease (Cooper et al. 2009; Zaharieva et al. 2012). It is therefore thought that RBPs play key roles in localizing functional splice sites. In particular, the abundant SR and hnRNP proteins have been attributed key roles in this process by forming RNA-protein complexes cotranscriptionally to recruit early splicosomal components for defining splice sites. Although SR proteins were initially viewed as binding ESEs to activate splicing, and hnRNP proteins to bind ISSs for antagonizing SR proteins, a number of genome-wide studies draw a more complex picture for both SR and hnRNP binding and function (Blanchette et al. 2009; Änkö et al. 2010, 2012; Huelga et al. 2012; Pandit et al. 2013; Brooks et al. 2015). In fact, both SR and hnRNP proteins can have very specific functions in one context, but also redundant functions in another context.

In this regard, we hypothesized that an array of similar exons as found in the Drosophila melanogaster Dscam gene would provide a platform for SR and hnRNP proteins to evolve exon-specific functions to regulate their inclusion. Surprisingly, however, Dscam exon 9 alternative splicing is exactly the opposite and the splicing pattern is very robustly maintained when SR and hnRNP proteins were either removed or overexpressed. In particular, the advances of Drosophila melanogaster genetics allowed us to use complete knockouts of most canonical SR and general hnRNP proteins and thus avoid the ambiguity of RNAi that would leave residual protein. Hence, despite complete loss of individual SR and hnRNP proteins, or combinations thereof, the Dscam splicing pattern is robustly maintained. conserved sequences have been found in the Dscam exon 6 cluster (Graveley 2005). Our previous analysis of the exon 4 cluster, and the in-depth analysis of the exon 9 cluster in this paper, however, rule out such a mechanism in these two clusters (Haussmann et al. 2019). Hence, the question remains whether two independent mechanisms arose to regulate mutually exclusive alternative splicing in Dscam variable clusters. Potentially, the conserved sequences present in the variable clusters could provide binding sites for RBPs that have adopted cluster-specific roles. In this context, it is interesting to note that deletion of the docking site in exon 6 leads to the inclusion of mostly the first exon in the cluster (May et al. 2011). This is unexpected as removal of the splicing activating mechanism should result in skipping of the entire variable cluster, because the proposed repressor hnRNP36 would still be present. Accordingly, the docking site in the exon 6 cluster also exerts a repressive role in maintaining the entire cluster in a repressed state.

Likewise, our finding that noncanonical Srrm234 regulates the inclusion of many variables in the Dscam exon 9 cluster suggests a mechanism in Dscam mutually exclusive alternative splicing that differs from more general splicing rules directed by canonical SR and general hnRNP proteins. One of the human homologs of Srrm234, SRRM4 has key roles in the regulation of microexons (Irimia et al. 2014). Due to their small size, microexons cannot be defined through the standard mechanism of exon definition. Hence, a distinct mechanism must apply, that can accurately direct splicing of microexons. Because microexons are often found in large introns, a robust process must underlie their selection and involves a newly described enhancer of microexons domain (eMIC), present in human SRRM3 and SRRM4. Intriguingly, in vertebrates, the ancestral prohomolog Srrm234 has duplicated into three genes to adopt distinct functions through dedicated protein domains, but these features are maintained by alternative 

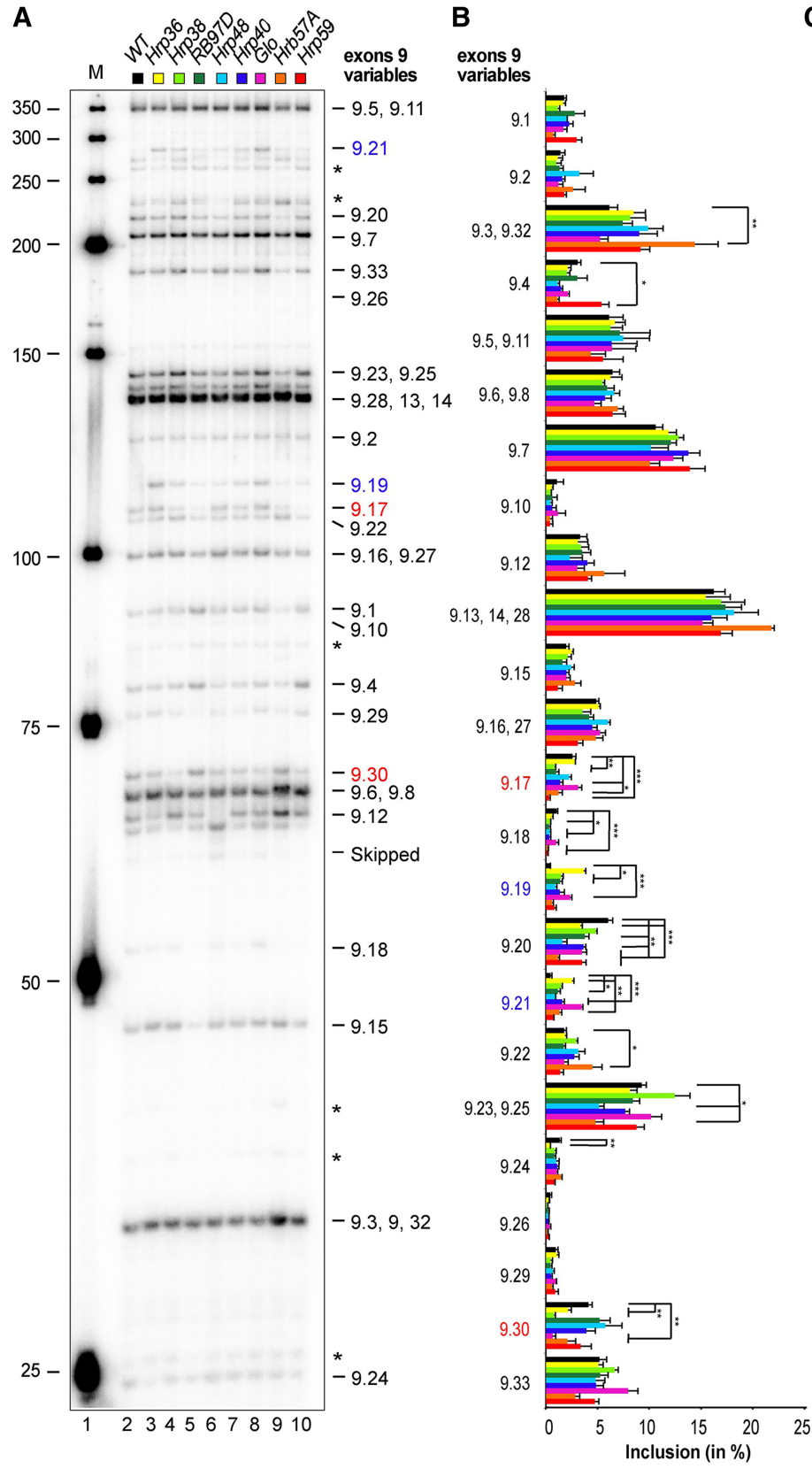

WT $\square$ Hrp38 $\square$ Hrp48 $\square$ Glo $\square$ Hrp59 $\square$ Hrp36 $\square$ RB97D $\square$ Hrp40 $\square$ Hrb57A
C

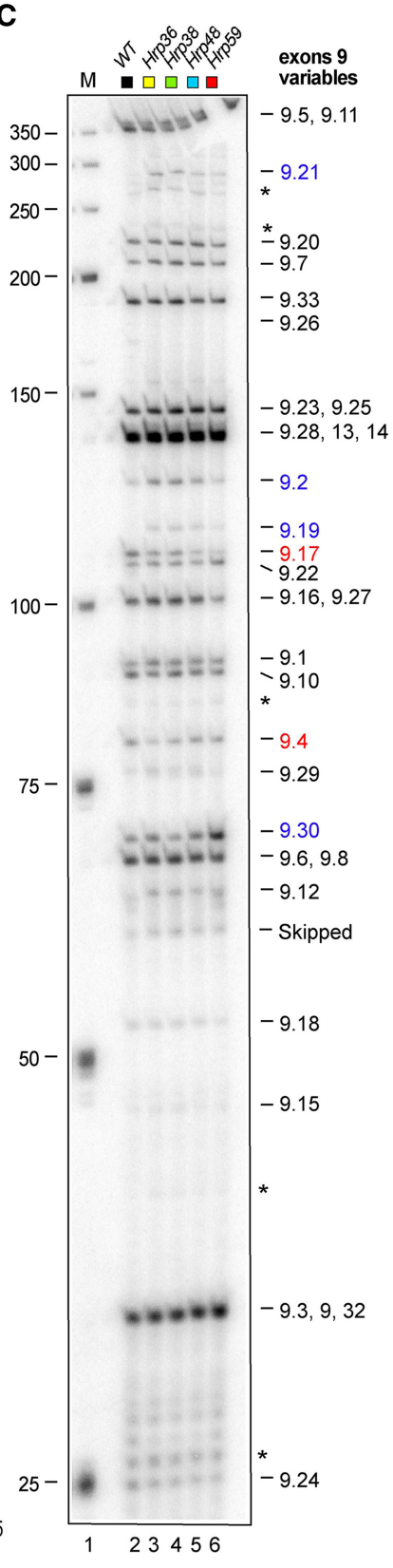

D
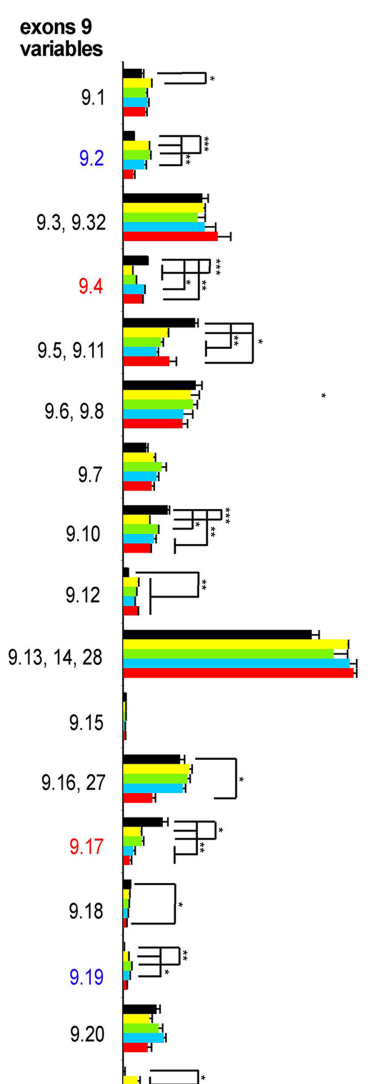

FIGURE 6. Analysis of Dscam exon 9 alternative splicing in general hnRNP protein LOF and GOF mutants. $(A, C)$ Denaturing acrylamide gel showing restriction digests of Dscam exon 9 variables amplified with a ${ }^{32} \mathrm{P}$ labeled forward primer from 14-18 $\mathrm{h}$ Drosophila embryos for general hnRNP protein LOF $(A)$ and elavGAL4 UAS GOF mutants (C). Quantification of inclusion levels are shown as means with standard error from three experiments for canonical SR protein LOF $(B)$ and GOF mutants $(D)$. Prominent changes in inclusion levels are marked with red letters for a decrease and in blue for an increase, and statistically significant differences are indicated by asterisks. $\left(^{* * *}\right) P \leq 0.001,\left({ }^{* *}\right) P \leq 0.01,\left(^{*}\right) P \leq 0.05$.

mRNA processing in Drosophila melanogaster Srrm234 to include the eMIC at the carboxyl terminus of the protein in neuronal tissue (Torres-Méndez et al. 2019).

Dscam alternative exons comply with the general average length of exons and thus the mechanism of their regulation is likely distinct from microexons. Dscam exon 9 cluster regulation by Srrm234 seems to involve its Cwf21 domain, which is not required for microexon inclusion (Torres-Méndez et al. 2019). Transposon inserts in the middle of the Srrm234 gene resulting in a truncated protein, that contains the Cwf21 domain do not affect exon 9 diver-

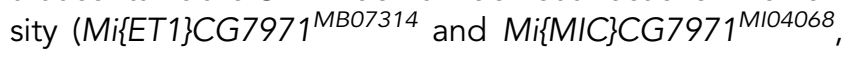


A

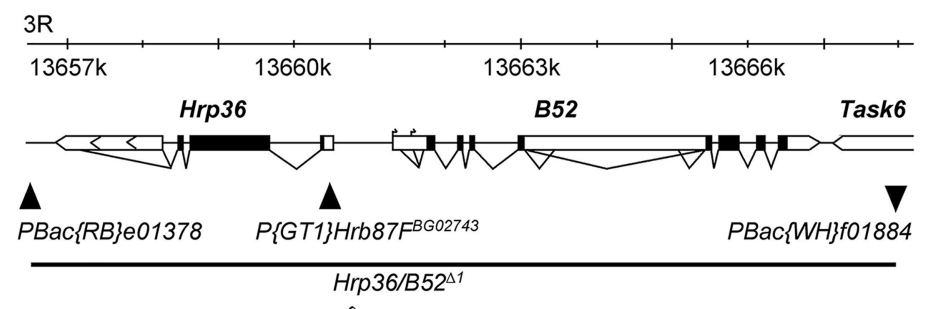

B

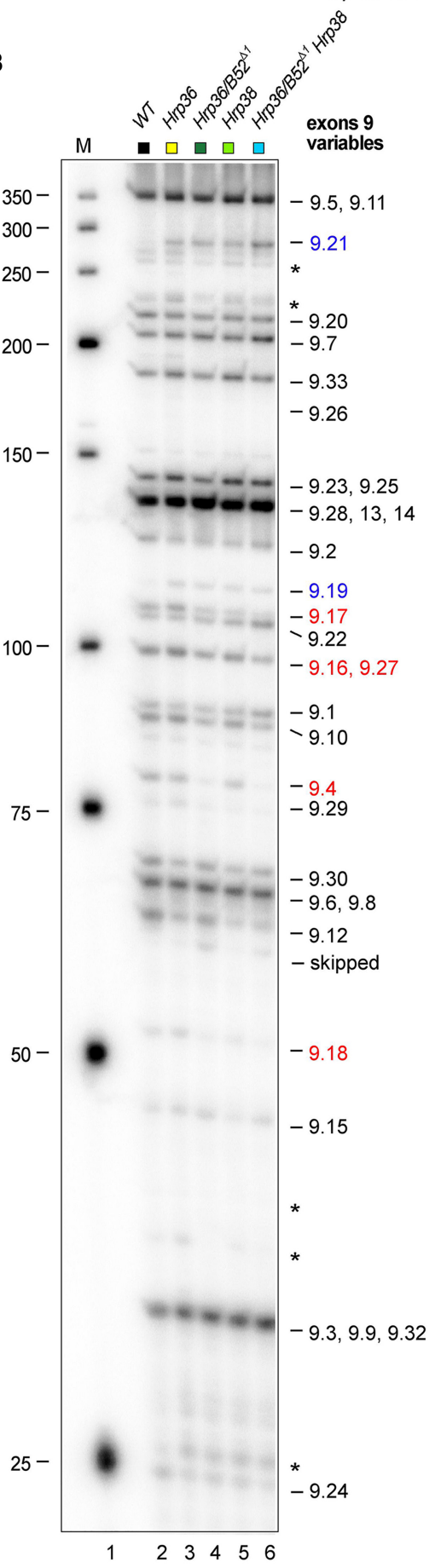

C

exons 9 variables
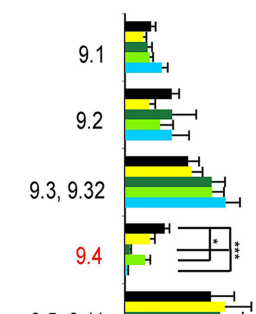

$9.5,9.11$

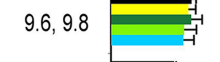
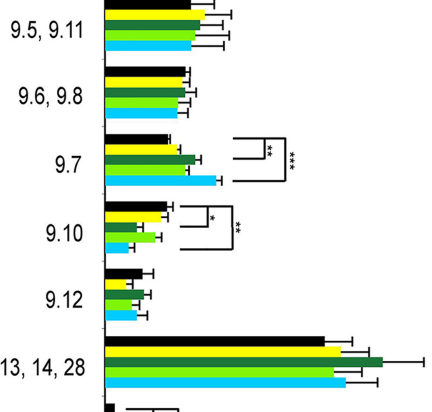

$9.13,14,28$
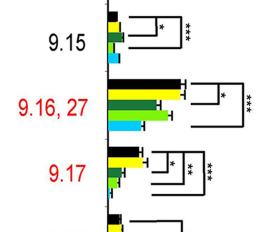

9.18
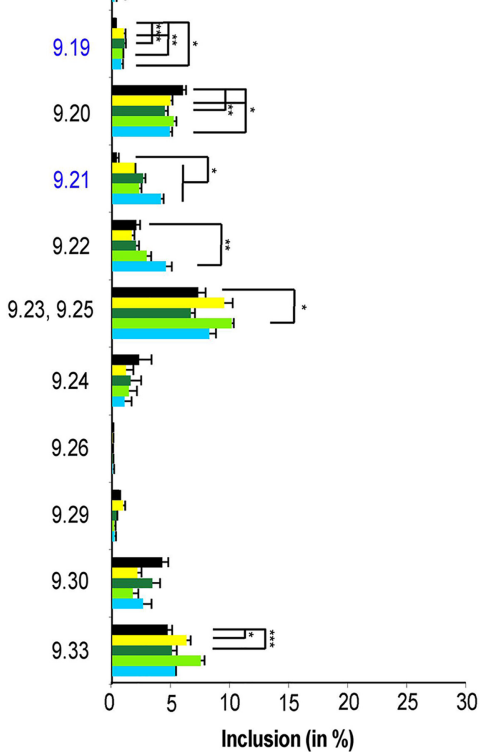

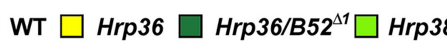

FIGURE 7. (Legend on next page) data not shown). The Cwf21 domain, which is homologous to the yeast Cwc21 domain, has been attributed key roles in splicing due to copurification of the human ortholog SRRM2 with active spliceosomes and its localization in the catalytic center of the spliceosome (Bessonov et al. 2008). Furthermore, the Cwc21 domain interacts with the U5 snRNP core components Snu114 and Prp8 involved in key structural rearrangements in the spliceosome during catalysis (Grainger et al. 2009; Gautam et al. 2015). Interestingly, Cwc21 has been attributed roles in splicing of meiotic genes which are regulated differently from general intron-containing genes (Gautam et al. 2015). Srrm2 forms a complex with Srrm1 to promote alternative splicing of Drosophila melanogaster doublesex required for sex determination, but the mechanism in Dscam is different as loss of Srrm1 does not impact on alternative splicing in the exon 9 cluster (Blencowe et al. 1998; Eldridge et al. 1999). In addition, Srrm234 also interacts with U1 70K, so potentially could act to activate the $5^{\prime}$ splice site and initiate the splicing process from a repressed state of the variable cluster (Guruharsha et al. 2011).

A Dscam cluster-specific role has been suggested for Hrp36 acting as a repressor preventing splicing together of exon 6 variables in S2 cells, but whether the results are the same in flies remains to be tested (Olson et al. 2007). Such a factor has not been identified for exon 4 and 9 clusters, and for the factors tested, we did not observe splicing together of variable exons. Intriguingly, a newly annotated exon 4.0 in the beginning of the bee Dscam exon 4 cluster is spliced to exon 4.6 (Decio et al. 2019). This unexpected finding, however, is not compatible with the model described for Hrp36 in the exon 6 cluster, but might involve a repressive sequence element around exon 4.0 similar to the element discovered in the beginning of the exon 6 cluster, which when deleted results only in inclusion of exon 
6.1 (May et al. 2011). Likewise, factors like Srrm234 would then act as activators to drive inclusion of variables.

Taken together, Dscam exon 9 mutually exclusive alternative splicing is robust against fluctuations in canonical SR and general hnRNP proteins arguing for a specific mechanism regulating inclusion levels of variable exons. Indeed, noncanonical SR protein Srrm234 plays a key role in increasing inclusion of many exon 9 variables. However, since Srrm234 does not have one of the classic RNA binding domains, additional RBPs likely connect Srrm234 to Dscam exon 9. Hence, our data obtained from knockouts of general splicing factors indicate that a small complement of RBPs are likely key regulators of Dscam mutually exclusive alternative splicing.

The gene structure of invertebrate Dscam harboring arrays of variable exons for mutually exclusive splicing is at the extreme, but arrays of several alternative exons are common to many genes in metazoans. Likely, a yet to be discovered feature of the spliceosome has been exploited in mutually exclusive alternative splicing of Dscam such that only one exon is chosen. Likewise, since sequences that look like splice sites are common in large introns, such a mechanism could be broadly relevant for robust select of isolated exons.

\section{MATERIALS AND METHODS}

\section{Fly genetics}

Flies were maintained on standard cornmeal agar food as previously described (Haussmann et al. 2013). CantonS was used as a wild-type control. The following LOF mutants were used as depicted in Supplemental Figures S1, S2, and Figure 7A: X16 (P\{GSV6\}Hrb27C ${ }^{G S 16784, ~ D G R C ~ K y o t o ~ \# 206763), ~ R B P 1 ~(P\{E P g\} ~}$ mRpL37HP37044, BDSC \#22011), RBP1-like (P\{GawB\}Rbp1like ${ }^{\text {NP0295 }}$, DGRC Kyoto \#103580), Srp54 (P\{GSV6\}Srp54 ${ }^{\text {GS15334, }}$ DGRC Kyoto \#206174), SC35 (P\{SUPor-P\}SC35 KG02986, BDSC

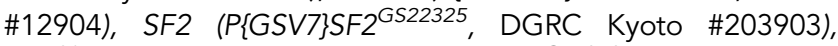

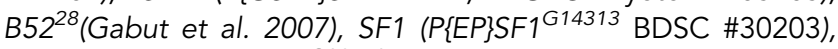
Hrp36 (P\{GT1\}Hrb87F ${ }^{B G 02743}$, BDSC \#12869), Hrp38 Mi\{MIC $\}$

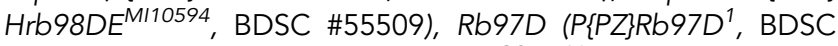
\#11782), Hrp48 (P\{GSV6\}Hrb27C ${ }^{G S 14498, ~ D G R C ~ K y o t o ~}$ \#205836), Hrp40 (P\{GSV6\}sqd ${ }^{G S 18188, ~ D G R C ~ K y o t o ~ \# 201020), ~}$ Glo (PBac\{WH\}glof02674, BDSC \#18576), Hrb57A (P\{EP\}HnRNP-

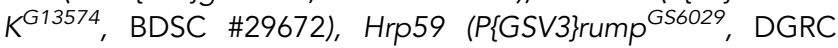

Kyoto \#200852), Srrm $1^{B 103}$ (SRm160 16103 , Fan et al. 2014), and Srrm $2340^{4 N}$. Since the transposon used for mutagenesis are large $(\sim 10 \mathrm{~kb})$, inserts in the transcribed part were considered to be null alleles, while inserts in promoter regions were considered hypomorphic alleles. If inserted in an intron transposons disrupt splicing, if inserted in the $5^{\prime}$ UTR they will prevent translation of the ORF, or if inserted in the ORF lead to a truncated nonfunctional protein. If inserted in the promotor region, transposon inserts reduce transcription. Whether lethality of mutants mapped to the locus was tested by crossing to chromosomal deficiencies.

The null-allele Srrm234 ${ }^{\Delta N}$ (CG7971) was generated by GenetiVision CRISPR gene targeting services. The $3.2 \mathrm{~kb}$ deletion at the amino terminus of the gene was generated using sgRNAs AGTCTGCTGGGGACACTGCT and CGCCGCAGGACATATAA CAG together with donor template harboring two homology arms flanking a loxP 3xP3-GFP loxP cassette. Left and right homology arms of the donor were amplified using primers CG7971-LAF1 (GTTCCGGTCTCTTAGCCCTGCAGCAGCTTCT GCTTG) and CG7971-LAR1 (TCCAAGGTCTCACAGTTTATAT GTCCTGCGGCGCTGC), and CG7971-RAF2 (GTTCCGGTCTCT GTCAGCTGGGAGCCGGCAGTGC) and CG7971-RAR2 (TCC AAGGTCTCAATCGAGTGGAGAACCCATACGTACTTAGATCC), respectively. Successful deletion and integration of the cassette was validated by $\mathrm{PCR}$ and Sanger sequencing using primers CG7971-outF1 (CATCGATTGTGTTGCATGAAGTTCAC) and CG7971-outR2 (GGGGAGTATCTGTGAGCAGTTGTATC), and LA-cassette-R (AAGTCGCCATGTTGGATCGACT), and Cassette-RA-F (CCTGGGCATGGATGAGCTGT), respectively. For the analysis of Dscam alternative splicing the 3xP3-GFP marker was removed by Cre mediated recombination using an insert on a third chromosome balancer $(T M 6 B, P\{w[+m C]=C r e w\} D H 2$, $\mathrm{Tb}, \mathrm{BDSC} \# 1501)$ and the resulting chromosome was rebalanced with a zygotically YFP- expressing balancer (TM6B, P\{Dfd-EYFP $\} 3$ Sb, Tb, BDSC \#8704) to collect the embryonic lethal homozygous mutants.

For GOF experiments the following UAS lines, gene switch vector inserts and EP lines were used: UAS GFP control line (Gabut et al. 2007), UAS GFP-X16 (Gabut et al. 2007), UAS RSF1 (Labourier et al. 1999), UAS GFP-SC35 (Gabut et al. 2007), UAS GFP-SF2 (Gabut et al. 2007), Srrm1 (P\{EP\}Srrm1 ${ }^{\text {G18603, BDSC }}$ \#26938), UAS GFP-B52 (Gabut et al. 2007), Hrp36 (P\{GSV6\} ${ }^{G S 15926}$, DGRC Kyoto \#206416), Hrp38 (P\{GSV6\} ${ }^{\mathrm{GS} 12795,}$

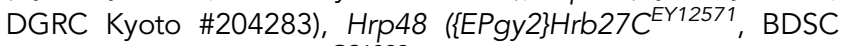
\#20758), Hrp59 (P\{GSV3\} ${ }^{\text {GS6029 }}$, DGRC Kyoto \#200852).

Hrp36 and B52 genes lie next to each other. The Hrp36/B52 ${ }^{41}$ double mutant was generated by FRT/FLP mediated recombination using PBac\{RB\}e01378 and PBac\{WH\}f01884 transposon insertions as previously described (Zaharieva et al. 2015). The lethal Hrp36/B52 ${ }^{41}$ allele was balanced and validated using primers e01378 Rev (GCCACATTTAGATGATTCAGCATTAT), f01884 Rev (GATTCCAATAGATCCCAAC CGTTTCG), and RB 3' MINUS (TCCAAG CGGCGACTGAGATG).

Lethal lines were rebalanced with balancers expressing YFP zygotically, but not maternally under a Dfd promoter (CyO, P\{Dfd-EYFP\}2, BDSC \#8578, TM6B, P\{Dfd-EYFP\}3 Sb, Tb, BDSC \#8704) to allow for the selection of homozygous lethal 
mutants. Non-GFP expressing 14-18 h embryos were further selected according to the morphology of the auto-fluorescing gut to distinguish them from homozygous balancer carrying animals, which die before they express GFP (Haussmann et al. 2008). For overexpression, a third chromosomal elavGAL4 insert was used $(P\{w[+m m C]=$ GAL4-elav. L $\} 3$, BDSC \#8760).

\section{RNA extraction, RT-PCR, restriction digestion, and denaturing acrylamide gels}

Total RNA was extracted using Tri-reagent (SIGMA) and reverse transcription was done with Superscript II (Invitrogen) as previously described (Koushika et al. 1999) using primer Dscam 11RT1 (CGGAGCCTATTCCATTGATAGCCTCGCACAG, 1 pmol/20 $\mu \mathrm{L}$ reaction). PCR to amplify Dscam exon 9 cluster was done using primers 8F1 (GATCTCTGGAAGTGCAAGTCATGG) and 10R1 $\Delta$ ST (GGCCTTATCGGTGGGCACGAGGTTCCATCTGGGA GGTA) for 37 cycles with $1 \mu \mathrm{L}$ of cDNA. Primers were labeled with ${ }^{32} \mathrm{P} \gamma$-ATP $(6000 \mathrm{Ci} / \mathrm{mmol}, 25 \mathrm{mM}$, PerkinElmer) with PNK (NEB) to saturation and diluted as appropriate. From a standard $\mathrm{PCR}$ reaction with a ${ }^{32} \mathrm{P}$ labeled forward primer, $10 \%-20 \%$ were sequentially digested with a mix of restriction enzymes (NEB) according to their buffer requirements and temperatures. $\mathrm{PCR}$ reaction and restriction digests were phenol/ $\mathrm{CHCl}_{3}$ extracted, ethanol precipitated in the presence of glycogen (Roche) and analyzed on standard $6 \%$ sequencing type denaturing polyacrylamide gels. After exposure to a phosphoimager (BioRad), individual bands were quantified using ImageQuant (BioRad) and inclusion levels for individual variable exons were calculated from the summed up total of all variables. Statistical analysis was done by one-way ANOVA followed by Tukey-Kramer post-hoc analysis using Graphpad prism. Percent inclusion levels of exon 9 variables of embryos were calculated from the total sum of variables. RNA in situs were obtained from flybase as previously described (Haussmann et al. 2008).

\section{Sequence analysis}

The in silico analysis for SELEX motif occurrence was done by plotting the scores from sliding window using a position weight matrix of the Drosophila melanogaster consensus sequence for a given RBP to the Dscam exon 9 variable cluster $(P<0.05$, Blanchette et al. 2009; Korhonen et al. 2009). The CLIP data was downloaded from GEO as deposited in (Blanchette et al. 2009), and the TiMAT window-scores have been used to generate the plot based on the version 4 of the genome assembly. Tiling arrays scores within the Dscam variable exon 9 cluster were plotted against all scores to determine whether the four Hrp proteins show significantly increased binding.

Vista alignments were generated as previously described (Haussmann et al. 2011). The exon 9 docking site was scanned against all gene sequences (as downloaded from FlyBase on the 26th of February 2019) using Blat (Version 35, parameters: -stepSize $=1$ tileSize $=6$-minScore $=0$-minldentity = 0, filtering for hits of at least bit-score of 30 and a coverage over the docking sequence of at least 20 residues) (Kent 2002).

In order to compare the docking site's propensity to form potential long-range base-pairing with other intronic Dscam sequences of the same length, we sampled 100 strictly intronic sequences of the same or higher sequence complexity as determined by Shannon entropy. We then used the BioPython Bio. pairwise2 local alignment implementation to get pairwise alignments against all (excluding the sampled sequenced and the docking sequence) reverse and reverse-complement subsequences of the same length in any Dscam intron, using a custom substitution matrix to allow for $\mathrm{G}-\mathrm{U}$ pairings (scoring scheme: $\mathrm{G} \rightarrow \mathrm{U}: 0.8, \mathrm{~A} \rightarrow \mathrm{U}: 1, \mathrm{G} \rightarrow \mathrm{C}: 1.2$, gap opening penalty 0.1 , gap extension penalty 0.1) (Cock et al. 2009). We then retained all hits with less than three gaps and normalized the alignment scores by each queries' potential highest score. To assess the best potential secondary structure formed by the docking sequence with any intronic sequence, we run the same sampled sequenced against the concatenated reverse and reverse complement intronic sequences of Dscam (masking each query) using RNAduplex from the Vienna package and obtained for each sequence the predicted lowest energy secondary structure prediction (Lorenz et al. 2011).

\section{SUPPLEMENTAL MATERIAL}

Supplemental material is available for this article.

\section{ACKNOWLEDGMENTS}

We thank Bloomington, Kyoto, and Harvard stock centers, J. Tazi and L. Rabinow for fly lines, and P. Grzechnik for comments on the manuscript. We acknowledge funding from the Sukran Sinan Memory Fund to P.U., the Biotechnology and Biological Sciences Research Council (BBSRC) and the European Research Council (ERC-StG-LS2-637591) to M.I.

Author contributions: M.S. and P.U. designed and directed the project. P.U., M.S., I.H., and H.L. performed experiments. A.T.-M. and M.I. generated and validated the Srrm $234^{\Delta N}$ allele. R.A. performed bioinformatic analysis. P.U. and M.S. wrote the manuscript. All authors read and approved the final manuscript.

Received March 20, 2019; accepted July 4, 2019.

\section{REFERENCES}

Änkö ML, Morales L, Henry I, Beyer A, Neugebauer KM. 2010. Global analysis reveals SRp20- and SRp75-specific mRNPs in cycling and neural cells. Nat Struct Mol Biol 17: 962-970. doi:10.1038/nsmb .1862

Änkö ML, Müller-McNicoll M, Brandl H, Curk T, Gorup C, Henry I, Ule J, Neugebauer KM. 2012. The RNA-binding landscapes of two SR proteins reveal unique functions and binding to diverse RNA classes. Genome Biol 13: R17. doi:10.1186/gb-2012-13-3r17

Appocher C, Mohagheghi F, Cappelli S, Stuani C, Romano M, Feiguin F, Buratti E. 2017. Major hnRNP proteins act as general TDP-43 functional modifiers both in Drosophila and human neuronal cells. Nucleic Acids Res 45: 8026-8045. doi:10.1093/nar/ gkx477

Bessonov S, Anokhina M, Will CL, Urlaub H, Lührmann R. 2008. Isolation of an active step I spliceosome and composition of its RNP core. Nature 452: 846-850. doi:10.1038/nature06842

Best A, Dalgliesh C, Kheirollahi-Kouhestani M, Danilenko M, Ehrmann I, Tyson-Capper A, Elliott DJ. 2014. Tra2 protein biology 
and mechanisms of splicing control. Biochem Soc Trans 42: 1152 1158. doi:10.1042/BST20140075

Black DL. 2003. Mechanisms of alternative pre-messenger RNA splicing. Annu Rev Biochem 72: 291-336. doi:10.1146/annurev biochem.72.121801.161720

Blanchette M, Green RE, MacArthur S, Brooks AN, Brenner SE, Eisen MB, Rio DC. 2009. Genome-wide analysis of alternative pre-mRNA splicing and RNA-binding specificities of the Drosophila hnRNP A/B family members. Mol Cell 33: 438-449. doi:10.1016/j.molcel.2009.01.022

Blencowe BJ, Issner R, Nickerson JA, Sharp PA. 1998. A coactivator of pre-mRNA splicing. Genes Dev 12: 996-1009. doi:10.1101/gad 12.7 .996

Blencowe BJ, Bowman JA, McCracken S, Rosonina E. 1999. SR-related proteins and the processing of messenger RNA precursors. Biochem Cell Biol 77: 277-291. doi:10.1139/099-048

Blencowe BJ, Baurén G, Eldridge AG, Issner R, Nickerson JA, Rosonina E, Sharp PA. 2000. The SRm160/300 splicing coactivator subunits. RNA 6: 111-120. doi:10.1017/S1355838200991982

Bradley T, Cook ME, Blanchette M. 2015. SR proteins control a complex network of RNA-processing events. RNA 21: 75-92. doi:10 $.1261 /$ rna.043893.113

Brooks AN, Duff MO, May G, Yang L, Bolisetty M, Landolin J, Wan K, Sandler J, Booth BW, Celniker SE, et al. 2015. Regulation of alternative splicing in Drosophila by 56 RNA binding proteins. Genome Res 25: 1771-1780. doi:10.1101/gr.192518.115

Busch A, Hertel KJ. 2012. Evolution of SR protein and hnRNP splicing regulatory factors. Wiley Interdiscip Rev RNA 3: 1-12. doi:10 .1002/wrna.100

Chen M, Manley JL. 2009. Mechanisms of alternative splicing regulation: insights from molecular and genomics approaches. Nat Rev Mol Cell Biol 10: 741-754. doi:10.1038/nrm2777

Cock PJ, Antao T, Chang JT, Chapman BA, Cox CJ, Dalke A, Friedberg I, Hamelryck T, Kauff F, Wilczynski B, et al. 2009. Biopython: freely available Python tools for computational molecular biology and bioinformatics. Bioinformatics 25: 1422-1423. doi:10.1093/bioinformatics/btp163

Cooper TA, Wan L, Dreyfuss G. 2009. RNA and disease. Cell 136: 777-793. doi:10.1016/j.cell.2009.02.011

Decio P, Ustaoglu P, Roat TC, Malaspina O, Devaud JM, Stöger R, Soller M. 2019. Acute Thiamethoxam exposure in Apis mellifera: absence of both stress-induced changes in mRNA splicing and synergistic effects of common fungicide and herbicide. bioRxiv doi: 10.1101/641407

Dong Y, Taylor HE, Dimopoulos G. 2006. AgDscam, a hypervariable immunoglobulin domain-containing receptor of the Anopheles gambiae innate immune system. PLoS Biol 4: e229. doi:10.1371/ journal.pbio.0040229

Eldridge AG, Li Y, Sharp PA, Blencowe BJ. 1999. The SRm160/300 splicing coactivator is required for exon-enhancer function. Proc Natl Acad Sci 96: 6125-6130. doi:10.1073/pnas.96.11.6125

Fan YJ, Gittis AH, Juge F, Qiu C, Xu YZ, Rabinow L. 2014. Multifunctional RNA processing protein SRm160 induces apoptosis and regulates eye and genital development in Drosophila. Genetics 197: 1251-1265. doi:10.1534/genetics.114 .164434

Fiszbein A, Kornblihtt AR. 2017. Alternative splicing switches: important players in cell differentiation. Bioessays 39: 1600157. doi:10 .1002/bies.201600157

Fu XD, Ares M Jr. 2014. Context-dependent control of alternative splicing by RNA-binding proteins. Nat Rev Genet 15: 689-701. doi:10.1038/nrg3778

Gabut M, Dejardin J, Tazi J, Soret J. 2007. The SR family proteins B52 and dASF/SF2 modulate development of the Drosophila visual system by regulating specific RNA targets. Mol Cell Biol 27: 3087-3097. doi:10.1128/MCB.01876-06

Gautam A, Grainger RJ, Vilardell J, Barrass JD, Beggs JD. 2015. Cwc21p promotes the second step conformation of the spliceosome and modulates 3' splice site selection. Nucleic Acids Res 43: 3309-3317. doi:10.1093/nar/gkv159

Geuens T, Bouhy D, Timmerman V. 2016. The hnRNP family: insights into their role in health and disease. Hum Genet 135: 851-867. doi:10.1007/s00439-016-1683-5

Grainger RJ, Barrass JD, Jacquier A, Rain JC, Beggs JD. 2009. Physical and genetic interactions of yeast $\mathrm{Cwc} 21 \mathrm{p}$, an ortholog of human SRm300/SRRM2, suggest a role at the catalytic center of the spliceosome. RNA 15: 2161-2173. doi:10.1261/rna.1908309

Graveley BR. 2005. Mutually exclusive splicing of the insect Dscam pre-mRNA directed by competing intronic RNA secondary structures. Cell 123: 65-73. doi:10.1016/j.cell.2005.07.028

Guruharsha KG, Rual JF, Zhai B, Mintseris J, Vaidya P, Vaidya N, Beekman C, Wong C, Rhee DY, Cenaj O, et al. 2011. A protein complex network of Drosophila melanogaster. Cell 147: 690703. doi:10.1016/j.cell.2011.08.047

Haussmann IU, White K, Soller M. 2008. Erect wing regulates synaptic growth in Drosophila by integration of multiple signaling pathways. Genome Biol 9: R73. doi:10.1186/gb-2008-9-4-r73

Haussmann IU, Li M, Soller M. 2011. ELAV-mediated 3'-end processing of ewg transcripts is evolutionarily conserved despite sequence degeneration of the ELAV-binding site. Genetics 189: 97-107. doi:10.1534/genetics.111.131383

Haussmann IU, Hemani Y, Wijesekera T, Dauwalder B, Soller M. 2013. Multiple pathways mediate the sex-peptide-regulated switch in female Drosophila reproductive behaviours. Proc Biol Sci 280: 20131938. doi:10.1098/rspb.2013.1938

Haussmann IU, Ustaoglu P, Brauer U, Hemani Y, Dix TC, Soller M. 2019. Plasmid-based gap-repair recombineered transgenes reveal a central role for introns in mutually exclusive alternative splicing in Down Syndrome Cell Adhesion Molecule exon 4. Nucleic Acids Res 47: 1389-1403. doi:10.1093/nar/gky1254

Hemani Y, Soller M. 2012. Mechanisms of Drosophila Dscam mutually exclusive splicing regulation. Biochem Soc Trans 40: 804-809. doi:10.1042/BST20120060

House AE, Lynch KW. 2006. An exonic splicing silencer represses spliceosome assembly after ATP-dependent exon recognition. Nat Struct Mol Biol 13: 937-944. doi:10.1038/nsmb1149

Huelga SC, Vu AQ, Arnold JD, Liang TY, Liu PP, Yan BY, Donohue JP, Shiue L, Hoon S, Brenner S, et al. 2012. Integrative genome-wide analysis reveals cooperative regulation of alternative splicing by hnRNP proteins. Cell Rep 1: 167-178. doi:10.1016/j.celrep.2012 .02 .001

Irimia M, Weatheritt RJ, Ellis JD, Parikshak NN, GonatopoulosPournatzis T, Babor M, Quesnel-Vallières $M$, Tapial J, Raj B, O'Hanlon D, et al. 2014. A highly conserved program of neuronal microexons is misregulated in autistic brains. Cell 159: 15111523. doi:10.1016/j.cell.2014.11.035

Kent WJ. 2002. BLAT-the BLAST-like alignment tool. Genome Res 12: 656-664. doi:10.1101/gr.229202

Korhonen J, Martinmäki P, Pizzi C, Rastas P, Ukkonen E. 2009. MOODS: fast search for position weight matrix matches in DNA sequences. Bioinformatics 25: 3181-3182. doi:10.1093/bioinfor matics/btp554

Koushika SP, Soller M, DeSimone SM, Daub DM, White K. 1999. Differential and inefficient splicing of a broadly expressed Drosophila erect wing transcript results in tissue-specific enrichment of the vital EWG protein isoform. Mol Cell Biol 19: 39984007. doi:10.1128/MCB.19.6.3998

Labourier E, Bourbon HM, Gallouzi IE, Fostier M, Allemand E, Tazi J. 1999. Antagonism between RSF1 and SR proteins for both splice- 
site recognition in vitro and Drosophila development. Genes Dev 13: 740-753. doi:10.1101/gad.13.6.740

Lim LP, Burge CB. 2001. A computational analysis of sequence features involved in recognition of short introns. Proc Natl Acad Sci 98: 11193-11198. doi:10.1073/pnas.201407298

Long JC, Caceres JF. 2009. The SR protein family of splicing factors: master regulators of gene expression. Biochem J 417: 15-27. doi:10.1042/BJ20081501

Lorenz R, Bernhart SH, Höner Zu Siederdissen C, Tafer H, Flamm C, Stadler PF, Hofacker IL. 2011. ViennaRNA Package 2.0. Algorithms Mol Biol 6: 26. doi:10.1186/1748-7188-6-26

Lührmann R, Stark H. 2009. Structural mapping of spliceosomes by electron microscopy. Curr Opin Struct Biol 19: 96-102. doi:10 $.1016 / j . s b i .2009 .01 .001$

May GE, Olson S, McManus CJ, Graveley BR. 2011. Competing RNA secondary structures are required for mutually exclusive splicing of the Dscam exon 6 cluster. RNA 17: 222-229. doi:10.1261/rna .2521311

Neves G, Zucker J, Daly M, Chess A. 2004. Stochastic yet biased expression of multiple Dscam splice variants by individual cells. Nat Genet 36: 240-246. doi:10.1038/ng1299

Nilsen TW, Graveley BR. 2010. Expansion of the eukaryotic proteome by alternative splicing. Nature 463: 457-463. doi:10.1038/ nature08909

Olson S, Blanchette M, Park J, Savva Y, Yeo GW, Yeakley JM, Rio DC, Graveley BR. 2007. A regulator of Dscam mutually exclusive splicing fidelity. Nat Struct Mol Biol 14: 1134-1140. doi:10.1038/ nsmb1339

Pandit S, Zhou Y, Shiue L, Coutinho-Mansfield G, Li H, Qiu J, Huang J, Yeo GW, Ares M Jr, Fu XD. 2013. Genome-wide analysis reveals SR protein cooperation and competition in regulated splicing. Mol Cell 50: 223-235. doi:10.1016/j.molcel.2013.03.001

Park JW, Parisky K, Celotto AM, Reenan RA, Graveley BR. 2004. Identification of alternative splicing regulators by RNA interference in Drosophila. Proc Natl Acad Sci 101: 15974-15979. doi:10.1073/pnas.0407004101

Schmucker D, Clemens JC, Shu H, Worby CA, Xiao J, Muda M, Dixon JE, Zipursky SL. 2000. Drosophila Dscam is an axon guidance receptor exhibiting extraordinary molecular diversity. Cell 101: 671-684. doi:10.1016/S0092-8674(00)80878-8

Shen H, Kan JL, Green MR. 2004. Arginine-serine-rich domains bound at splicing enhancers contact the branchpoint to promote pre- spliceosome assembly. Mol Cell 13: 367-376. doi:10.1016/ S1097-2765(04)00025-5

Soller M. 2006. Pre-messenger RNA processing and its regulation: a genomic perspective. Cell Mol Life Sci 63: 796-819. doi:10 .1007/s00018-005-5391-x

Sun W, You X, Gogol-Döring A, He H, Kise Y, Sohn M, Chen T, Klebes A, Schmucker D, Chen W. 2013. Ultra-deep profiling of alternatively spliced Drosophila Dscam isoforms by circularizationassisted multi-segment sequencing. EMBO J 32: 2029-2038. doi:10.1038/emboj.2013.144

Szymczyna BR, Bowman J, McCracken S, Pineda-Lucena A, Lu Y, Cox B, Lambermon $M$, Graveley BR, Arrowsmith $\mathrm{CH}_{\text {, }}$ Blencowe BJ. 2003. Structure and function of the PWI motif: a novel nucleic acid-binding domain that facilitates pre-mRNA processing. Genes Dev 17: 461-475. doi:10.1101/gad.1060403

Torres-Méndez A, Bonnal S, Marquez $Y$, Roth J, Iglesias $M$, Permanyer J, Almudí I, O'Hanlon D, Guitart T, Soller M, et al. 2019. A novel protein domain in an ancestral splicing factor drove the evolution of neural microexons. Nat Ecol Evol 3: 691-701. doi:10.1038/s41559-019-0813-6

Wang Z, Xiao X, Van Nostrand E, Burge CB. 2006. General and specific functions of exonic splicing silencers in splicing control. Mol Cell 23: 61-70. doi:10.1016/j.molcel.2006.05.018

Wang ET, Sandberg R, Luo S, Khrebtukova I, Zhang L, Mayr C, Kingsmore SF, Schroth GP, Burge CB. 2008. Alternative isoform regulation in human tissue transcriptomes. Nature 456: 470476. doi:10.1038/nature07509

Watson FL, Puttmann-Holgado R, Thomas F, Lamar DL, Hughes M, Kondo M, Rebel VI, Schmucker D. 2005. Extensive diversity of Ig-superfamily proteins in the immune system of insects. Science 309: 1874-1878. doi:10.1126/science.1116887

Yang Y, Zhan L, Zhang W, Sun F, Wang W, Tian N, Bi J, Wang H, Shi D, Jiang $Y$, et al. 2011. RNA secondary structure in mutually exclusive splicing. Nat Struct Mol Biol 18: 159-168. doi:10.1038/ nsmb.1959

Zaharieva E, Chipman JK, Soller M. 2012. Alternative splicing interference by xenobiotics. Toxicology 296: 1-12. doi:10.1016/j.tox 2012.01.014

Zaharieva E, Haussmann IU, Bräuer U, Soller M. 2015. Concentration and localization of co-expressed ELAV/Hu proteins control specificity of mRNA processing. Mol Cell Biol 35: 3104-3115. doi:10 $.1128 /$ MCB.00473-15 

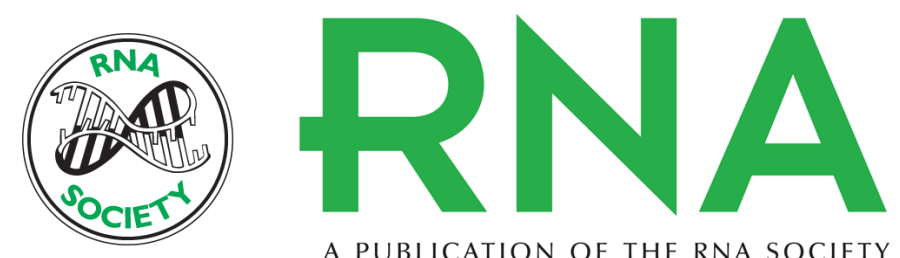

A PUBLICATION OF THE RNA SOCIETY

\section{Srrm234, but not canonical SR and hnRNP proteins, drive inclusion of Dscam exon 9 variable exons}

Pinar Ustaoglu, Irmgard U. Haussmann, Hongzhi Liao, et al.

RNA 2019 25: 1353-1365 originally published online July 10, 2019

Access the most recent version at doi:10.1261/rna.071316.119

\section{Supplemental http://rnajournal.cshlp.org/content/suppl/2019/07/10/rna.071316.119.DC1 \\ Material}

References This article cites 62 articles, 22 of which can be accessed free at: http://rnajournal.cshlp.org/content/25/10/1353.full.html\#ref-list-1

Creative This article is distributed exclusively by the RNA Society for the first 12 months after the Commons

License full-issue publication date (see http://rnajournal.cshlp.org/site/misc/terms.xhtml). After 12 months, it is available under a Creative Commons License (Attribution-NonCommercial 4.0 International), as described at http://creativecommons.org/licenses/by-nc/4.0/. Email Alerting $\begin{aligned} & \text { Receive free email alerts when new articles cite this article - sign up in the box at the } \\ & \text { Service }\end{aligned}$ top right corner of the article or click here. 